\title{
Altered Intracortical Inhibition in Chronic Traumatic Diffuse Axonal Injury
}

\begin{abstract}
Cintya Yukie Hayashi ${ }^{*}$, Iuri Santana Neville', Priscila Aparecida Rodrigues', Ricardo Galhardoni',2, André Russowsky Brunoni ${ }^{3}$, Ana Luiza Zaninotto ${ }^{1,4}$, Vinicius Monteiro de Paula Guirado', Ana Sofia Cueva1, Daniel Ciampi de Andrade', Manoel Jacobsen Teixeira ${ }^{1}$ and Wellingson Silva Paiva ${ }^{1}$
\end{abstract}

'Department of Neurology, School of Medicine, University of São Paulo (USP), São Paulo, Brazil, ${ }^{2}$ School of Medicine, Universidade da Cidade de São Paulo (UNICID), São Paulo, Brazil, ${ }^{3}$ Service of Interdisciplinary Neuromodulation, Institute of Psychiatry, Hospital das Clínicas HCFMUSP, University of São Paulo (USP), São Paulo, Brazil, “Division of Psychology, Hospital das Clínicas HCFMUSP, University of São Paulo (USP), São Paulo, Brazil

Background: Overactivation of NMDA-mediated excitatory processes and excess of GABA-mediated inhibition are attributed to the acute and subacute phases, respectively, after a traumatic brain injury (TBI). However, there are few studies regarding the circuitry during the chronic phase of brain injury.

Objective: To evaluate the cortical excitability (CE) during the chronic phase of TBI in victims diagnosed with diffuse axonal injury (DAl).

Methods: The 22 adult subjects were evaluated after a minimum of 1 year from the onset of moderate or severe TBI. Each of the subjects first had a comprehensive neuropsychological assessment to evaluate executive functions - attention, memory, verbal fluency, and information processing speed. Then, CE assessment was performed with a circular coil applying single-pulse and paired-pulse transcranial magnetic stimulation over the cortical representation of the abductor pollicis brevis muscle on $\mathrm{M} 1$ of both hemispheres. The CE parameters measured were resting motor threshold (RMT), motorevoked potentials (MEPs), short-interval intracortical inhibition (SIICl), and intracortical facilitation (ICF). All data were compared with that of a control group that consisted of the healthy age-matched individuals.

Results: No significant differences between the left and right hemispheres were detected in the DAI subjects. Therefore, parameters were analyzed as pooled data. Values of RMT, MEPs, and ICF from DAI patients were within normal limits. However, SIICI values were higher in the DAl group-DAI SIICI $=1.28(1.01 ; 1.87)$ versus the control value $=0.56$ (0.33; 0.69) - suggesting that they had a disarranged inhibitory system $(p<0.001)$. By contrast, the neuropsychological findings had weak correlation with the CE data.

Conclusion: As inhibition processes involve GABA-mediated circuitry, it is likely that the DAl pathophysiology itself (disruption of axons) may deplete GABA and contribute to ongoing disinhibition of these neural circuits of the cerebrum during the chronic phase of DAl.

Keywords: brain injuries, craniocerebral trauma, diffuse axonal injury, neurophysiology, transcranial magnetic stimulation 


\section{INTRODUCTION}

Traumatic brain injury (TBI) is one of the major health consequences of trauma from motor vehicle accidents having its highest incidence among young male adults $(1,2)$. Considering that this age group is at its prime economic productivity, should they suffer a TBI which can cause long-term motor and cognitive disabilities, the negative impact of TBI stretches beyond just the individual victim $(3,4)$.

Traumatic brain injury is classified by clinical severity (mild, moderate, or severe), pathoanatomic type (focal or diffuse), and mechanism of injury (blunt or penetrating) (1). Focal lesions tend to have simpler management compared to diffuse injuries, whereas widespread damage has a complex mechanism that contributes to morbidity and limits clinical study and management.

Diffuse axonal injury (DAI) is a clinical condition often related to closed head traumas. It is the predominant finding in approximately half of TBI patients, and it has been found in all levels of TBI severity. Clinically, trauma victims with prolonged unconsciousness (6 $\mathrm{h}$ or more) unaccompanied by ischemic damage or mass lesions are usually diagnosed with DAI. Still, most of the features of DAI are microscopic and cannot be identified on conventional methods of neuroimaging, such as computed tomography (CT) scans or conventional magnetic resonance imaging $(\mathrm{MRI})(1,5,6)$.

The diagnosis of DAI can only be confirmed by postmortem histopathological analysis and, for this reason, the development of new and more refined techniques-for instance, diffusionweighted imaging and diffusion tensor imaging in MRI-enables further studies of DAI in vivo. In particular, transcranial magnetic stimulation (TMS) seems to be an interesting tool for neurophysiological testing as it allows a noninvasive real-time study of the brain, providing indirect information about intracortical interneuronal circuits through cortical excitability (CE) assessments $(6-10)$.

Some studies using TMS show changes in CE after strokes, in psychiatric disorders, in pain syndromes, and even during acute phases of TBI (11-14). Mechanisms of intracortical facilitation (ICF) and intracortical inhibition are related to glutamatergic and GABAergic pathways, respectively, and the imbalance of these neurotransmitters is somehow involved in maladaptive plasticity $(15,16)$. Knowledge about how these imbalances lead to the pathophysiology that develops after brain injury would enable the development of new therapeutic strategies and rehabilitation options.

Unfortunately, there are few studies of CE after TBI, and most of those studies were carried out in patients with TBI of mild severity or only during the acute phase (14-16). Thus, in the present study, we sought to evaluate $\mathrm{CE}$ in patients during the chronic phase of TBI, diagnosed with DAI, using the diagnostic mode of TMS. In addition, we tried to correlate the neuropsychological profile of these patients with the CE data and clinical characteristics.

\section{MATERIALS AND METHODS}

\section{Setting and Subjects}

A convenience sample of 73 adults, $18-60$ years old, of both genders, who had been clinically diagnosed with DAI during an acute hospitalization following trauma were initially evaluated at the neurotrauma outpatient center of a tertiary referral hospital in Sao Paulo, Brazil.

After this initial screening, 51 patients were excluded. Exclusion criteria included (1) associated focal lesions or the presence of any abnormality other than DAI (e.g., epidural/ subdural hematoma); (2) having suffered more than one TBI; (3) major psychiatric disorders (e.g., major depression, bipolar disorder, any disorder requiring admission to a psychiatric ward); (4) history of surgical procedures to the brain/skull; (5) the presence of metallic devices/pieces in the brain/skull (clips, plates, electrodes, etc.); (6) pregnancy; (7) epilepsy/seizures; (8) severe language impairment (writing/reading/speaking); or (9) illicit drug and/or alcohol abuse.

To achieve the most homogeneous sample possible, DAI diagnosis was established for this study as (1) a clinical condition of prolonged unconsciousness ( $6 \mathrm{~h}$ or more) following TBI; (2) a head CT scan image taken during acute hospitalization, demonstrating a wide spectrum of findings such as a relatively normal examination, small hemorrhagic (hyperdense) or non-hemorrhagic (hypodense) lesions no more than $25 \mathrm{~cm}^{3}$ in size (typically located at the gray-white matter junction, in the corpus callosum, and in more severe cases in the brainstem); small intraventricular hemorrhage, subarachnoid hemorrhage, and signs of brain swelling, such as compressed or even absent basal cisterns; (3) MRI obtained during the chronic phase (i.e., taken at least 6 months after TBI), demonstrating small regions of susceptibility artifact at the gray-white matter junction, in the corpus callosum, or the brain stem. Some lesions might be entirely non-hemorrhagic (even using susceptibility-weighted imaging sequences at high-field strengths). These would, however, be visible as regions of high fluid-attenuated inversion recovery signals on an MRI of the cranium.

Twenty-two subjects selected to participate in this exploratory study were assessed after a 1-year interval, at least, from the moment of trauma. The recruitment period was from May 2014 to 2015. For general comparisons, we used the normative data of $\mathrm{CE}$ as reference (17), and for supplementary analysis, we selected a control group consisting of 22 healthy subjects, with no history of brain injury or trauma, from a normative CE database (17), matching the DAI subjects for age and gender.

The protocol was approved by the Ethics Committee for Research of the respective institutions (Protocol \#707.642), in compliance with the Declaration of Helsinki, and written informed consent was obtained from all the subjects participating in the study.

\section{Neuropsychological Assessment}

All of the selected patients underwent a broad neuropsychological assessment to evaluate attention, memory, information processing speed, dexterity, and executive functions (inhibitory control, verbal fluency, and working memory). All the neuropsychological tests were conducted at one session in a quiet room, with only the subject and the examiner, at 2-7 days before the CE assessment and included the following:

- STAI (State-Trait Anxiety Inventory) $(18,19)$,

- BDI (Beck Depression Inventory) $(18,20)$, 
- HVLT (Hopkins Verbal Learning Test)_immediate recall/ delayed recall/recognition (21),

- BVMT (Brief Visual Memory Test) - immediate recall/delayed recall/recognition (21),

- TMT A and B (Trail-Making Test parts A and B) focused visual attention and task-switching attention (22),

- Stroop test, Victoria version-selective attention and inhibition (22),

- Digit Span Test-working memory (23),

- COWAT (Controlled Oral Word Association Test) - phonologic and semantic verbal fluency (24),

- Symbol digit test-information processing speed (24),

- Five-point test-visual fluency (24),

- Grooved pegboard test-dexterity (25).

\section{CE Assessment: TMS}

The CE assessment was performed using MagPro X100 (MagVenture Tonika Elektronik, Farum, Denmark) with a C-100 circular coil connected to an electromyography amplifier of a one-channel, three-surface electrode output.

The stimulation target-hotspot-was determined using 70\% intensity to identify the point of highest response of the hand muscles, which would correspond to the cortical representation of the abductor pollicis brevis muscle on M1 of both hemispheres. Each subject sat comfortably on a reclining armchair and wore a polyester swim cap on which the hotspot was marked.

The parameters measured were resting motor threshold (RMT), motor-evoked potentials (MEPs), short-interval intracortical inhibition (SIICI), and ICF. Peak-to-peak MEP amplitudes were considered in microvolts $(\mu \mathrm{V})$. RMT was established as the lowest intensity at which MEP of at least $50-\mu \mathrm{V}$ amplitude could be elicited in 5 of 10 consecutive stimuli $(13,17,26-30)$.

We used single-pulse TMS for RMT and MEP measurements. The average value of four MEP curves taken at $120 \%$ of RMT was used for analysis. The same procedure was adopted for MEP curves at $140 \%$ of RMT. Paired-pulse TMS (pp-TMS) was used for SIICI and ICF measurements, with the conditioning stimulus set at $80 \%$ of RMT and the test stimulus at $120 \%$ of RMT (13). For SIICI analysis, response curves were taken using pp-TMS with 2 and 4 millisecond (ms) intervals between pulses [interstimulus intervals (ISI)], denominated ICI $2 \mathrm{~ms}$ and ICI $4 \mathrm{~ms}$. As for ICF, ISI were 10 and $15 \mathrm{~ms}$, denominated ICI $10 \mathrm{~ms}$ and ICI $15 \mathrm{~ms}$. The average value of four MEP curves at each interval was used for analysis. CE measurements were performed using the same technique as in previous studies to facilitate comparison $(17,26-30)$.

\section{Statistical Analysis}

All neuropsychological and CE data were analyzed using the SPSS version 22.0 Statistical package (SPSS, IBM Inc., Chicago, IL, USA) with two-tailed tests and a 5\% level of significance. Shapiro-Wilk tests were used to verify continuous variables for normal distribution, and Wilcoxon tests were used to compare the right and left hemispheres in the DAI group.

For inferential analysis, all subjects from DAI group were matched by age and gender to healthy subjects from a normative database of CE (17), and a Mann-Whitney $U$-test was performed.
The Spearman test was performed to analyze correlation between neuropsychological and CE data results.

\section{RESULTS}

\section{Demographic and Clinical Characteristics}

Most participants had severe TBI. They were mostly young adult males (86\%), as trauma in general is common in this group. For the outcome measure (functionality), participants were classified according to the Glasgow Outcome Scale-Extended (31). Most of them were independent, both inside and outside their homes but could not resume all their pre-injury social activitiesupper moderate disability - mostly due to irritability, concentration problems, and memory failures (Table 1).

Three subjects had used medications in the past that could interfere with the neurophysiological tests, but by the time they were included in the study, they were no longer taking any medications and were not outliers on CE data. Therefore, they were not excluded from analysis.

\section{CE Results}

The CE data distribution was skewed, and there were no significant differences between hemispheres $(p=0.125)$. A pooled analysis was performed in which data from both hemispheres (left and right) were combined (22 subjects, 44 hemispheres). One subject had traumatic amputation of the right arm, and CE data of the left hemisphere were not collected. Another subject had a brachial plexus injury of the left arm, and CE data of right hemisphere were not collected. In summary, 42 hemispheres were analyzed for the DAI patients.

\section{DAI Group Data Classified According to Normative Data}

On a group analysis, CE values for the DAI group were classified according to normative data (Table 2). The confidence interval

TABLE 1 | Demographic and clinical characteristics of 22 subjects with DAI.

Mean $( \pm S D)$ or number $(\%)$

\begin{tabular}{lc}
\hline Demographic & \\
Age, years & $30.1( \pm 10.3)$ \\
Gender, male & $19(86.36)$ \\
Education, years & $10.3( \pm 2.3)$ \\
Clinical characteristics & \\
Handedness, right & $20(90.9)$ \\
Time since TBl, months & $18.7( \pm 2.5)$ \\
Glasgow Outcome Scale-Extended & \\
5-Lower Moderate Disability & $2(9.09)$ \\
6-Upper Moderate Disability & $10(45.45)$ \\
7-Lower Good Recovery & $7(31.82)$ \\
8-Upper Good Recovery & $3(13.64)$ \\
Glasgow Coma Scale, score <8 at admission & $16(72.73)$ \\
Mechanisms of injury & \\
Automobile accident & $9(40.91)$ \\
Motorcycle accident & $8(36.36)$ \\
Running-over & $3(13.64)$ \\
Interpersonal aggression & $2(9.09)$ \\
Medication & \\
None & $19(86.36)$ \\
Benzodiazepine (prior use) & $2(9.09)$ \\
Antidepressant (prior use) & $1(4.55)$
\end{tabular}


TABLE 2 | CE data comparison between DAl patients and healthy controls, analyzed according to normative data.

\begin{tabular}{|c|c|c|c|c|c|c|c|}
\hline \multirow[t]{2}{*}{ CE parameters } & \multicolumn{2}{|c|}{ Median $(95 \% \mathrm{Cl})$} & \multirow[t]{2}{*}{$p$-Value } & \multirow[t]{2}{*}{$95 \% \mathrm{Cl}$ normative data $(17)^{\mathrm{a}}$} & \multicolumn{3}{|c|}{ Classification of DAl patients $n(\%)$} \\
\hline & Control $(n=44)$ & $\mathrm{DAI}(n=42)$ & & & High & Normal & Low \\
\hline $\mathrm{RMT}$ & $48.5(44 ; 52)$ & $47.5(43 ; 51)$ & 0.604 & $46.3-49.8$ & $19(45.24)$ & $3(7.14)$ & $20(47.62)$ \\
\hline MEP-120\% & $310.5(260.03 ; 436.52)$ & 435.85 (253.38; 581.28) & 0.388 & $423.3-689.6$ & $11(26.19)$ & $11(26.19)$ & $20(47.62)$ \\
\hline MEP-140\% & $756.5(592.31 ; 1,300)$ & 1,000 (742.02; 1,385.64) & 0.346 & $987.0-1,385.7$ & $15(35.71)$ & $9(21.43)$ & $18(42.86)$ \\
\hline Ratio 140/120 & $2.02(1.80 ; 3.16)$ & $2.46(1.79 ; 3.12)$ & 0.853 & 2.4-3.3 & $11(26.19)$ & $11(26.19)$ & $20(47.62)$ \\
\hline $\mathrm{ICl} 2 \mathrm{~ms}$ & $0.26(0.20 ; 0.47)$ & $1.28(0.79 ; 1.70)$ & $<0.001$ & $0.2-0.4$ & 36 (85.71) & $5(11.90)$ & $1(2.38)$ \\
\hline $\mathrm{ICl} 4 \mathrm{~ms}$ & $0.36(0.28 ; 0.62)$ & $1.17(1.0 ; 1.84)$ & $<0.001$ & $0.4-0.6$ & 36 (85.71) & $5(11.90)$ & $1(2.38)$ \\
\hline ICF $10 \mathrm{~ms}$ & $1.31(0.91 ; 1.77)$ & $1.20(0.94 ; 1.57)$ & 0.638 & $1.5-2.1$ & 7 (16.67) & $10(23.81)$ & $25(59.52)$ \\
\hline ICF $15 \mathrm{~ms}$ & $1.15(0.87 ; 1.37)$ & $1.47(1.18 ; 1.88)$ & 0.131 & $1.4-2.1$ & $12(28.57)$ & $11(26.19)$ & $19(45.24)$ \\
\hline $\mathrm{SIICl}$ & 0.56 (0.33; 0.69) & $1.28(1.01 ; 1.87)$ & $<0.001$ & $0.4-0.6$ & 36 (85.71) & $4(9.52)$ & $2(4.76)$ \\
\hline ICF & $1.13(0.96 ; 1.48)$ & $1.40(1.10 ; 1.68)$ & 0.432 & $1.5-2.0$ & $10(23.81)$ & $10(23.81)$ & $22(52.38)$ \\
\hline
\end{tabular}

aNormative data 95\% Cl obtained by Cueva (17).

RMT, Resting motor threshold; MEP-120\%, Motor-evoked potential at 120\% of RMT; MEP-140\%, Motor-evoked potential at 140\% of RMT; Ratio 140/120, Motor-evoked potential amplitude ratio for stimulus intensity at 140 and $120 \%$ of RMT; ICl 2 ms, Motor-evoked potential amplitude ratio for 2 ms ISI and 120\% of RMT; ICl 4 ms, Motor-evoked potential amplitude ratio for $4 \mathrm{~ms}$ ISI and 120\% of RMT; ICF $10 \mathrm{~ms}$, Motor-evoked potential amplitude ratio for $10 \mathrm{~ms}$ ISI and $120 \%$ of RMT; ICF $15 \mathrm{~ms}$, Motor-evoked potential ratio for 15 ms ISI and 120\% of RMT; SIICI, Short-interval intracortical inhibition; ICF, intracortical facilitation; Cl, confidence interval.

range of normal values obtained by Cueva and collaborators (17) was utilized to classify CE results for each parameter of each patient. Values above the highest confidence limit were classified as "high," those within the confidence interval were classified as "normal," and those under the lowest limit were classified as "low."

For each CE parameter, there were patients with higher/ lower values than normative data ones. For RMT values, there were 39 hemispheres (92.86\%) out of common healthy values (normative data); for MEP-120\% values, there were 31 hemispheres (73.81\%); for MEP-140\%, there were 33 hemispheres (78.57\%); for Ratio 140/120, there were 31 hemispheres (73.81\%); for ICI $2 \mathrm{~ms}$, there were 37 hemispheres $(88.09 \%)$; for ICI $4 \mathrm{~ms}$, there were also 37 hemispheres (88.09\%); for ICF $10 \mathrm{~ms}$, there were $32(76.19 \%)$; for ICF $15 \mathrm{~ms}$, there were 31 (73.81\%); for SIICI, there were $38(90.47 \%)$, and for ICF, there were $32(76.19 \%)$.

\section{DAI Patients Compared to Healthy Controls}

When data from the DAI patients on an individual level were analyzed, the difference on SIICI and its components was indeed statistically significant compared to those of healthy subjects (Table 2). Normal SIICI values usually range from 0.0 to 1.0 , and our results showed SIICI median values of $1.28(1.01 ; 1.87)$ (Figure 1).

\section{Neuropsychological Results}

The majority of neuropsychological tests of patients with DAI showed mean raw scores below the average expected for healthy individuals in our country. Assessments of HVLT, BVMT (immediate and delayed recall), TMT, Stroop, COWAT, Symbol Digit, Five Points, and Grooved Pegboard indicated that DAI patients were cognitively impaired considering age and/or years of schooling. On the other hand, full Digit Span test and only the recognition part of BVMT showed results within the normative average. Table 3 presents mean scores of neuropsychological assessment. Each test has a standard score limit that defines normal and/or impaired function.

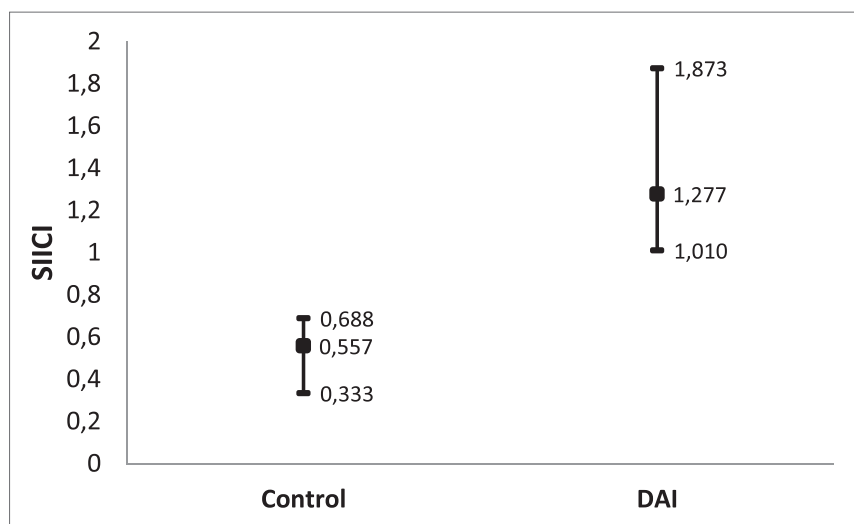

FIGURE 1 | Short-interval intracortical inhibition (SIICl) median values and $95 \% \mathrm{Cl}$ of diffuse axonal injury (DAl) patients compared to healthy subjects.

The hypothesis from the SIICI information and neuropsychological findings was that both of these could somehow be related via effects on inhibitory processes. For that reason, a correlation analysis was attempted using tests that assessed selective attention and inhibition (Table 4), but only weak correlations were found, though, and few of them were statistically significant (Figures 2-4).

\section{DISCUSSION}

From a pathophysiologic perspective on DAI, damage to axons occurs at the moment of trauma (primary axotomy) when abrupt acceleration-deceleration of the cranium results in shear forces and tensile strains on the white matter, generating small loci of hemorrhage. The resulting axonal degeneration can last for many hours after the trauma episode (caused by secondary axotomy and biochemical cascades) $(1,5,6)$.

To minimize the influence of inflammation on these neurophysiological changes, and focus on the direct neuronal damage, we selected subjects during the chronic phase of DAI (at least 1 
TABLE 3 | Results of the neuropsychological tests and inventories.

\begin{tabular}{|c|c|c|c|c|}
\hline Tests/inventory & & $n$ & $\begin{array}{c}\text { Mean } \\
\text { Raw score (SD) }\end{array}$ & $\begin{array}{c}\text { Mean } \\
\text { Z-score (SD) }\end{array}$ \\
\hline STAl & - & 21 & $54.14(8.79)$ & - \\
\hline $\mathrm{BDI}$ & - & 21 & 14.19 (12.03) & - \\
\hline \multirow[t]{3}{*}{ HVLT } & Immediate recall & 22 & $17.68(4.19)$ & $-1.79(1.06)$ \\
\hline & Delayed recall & 22 & $5.23(2.79)$ & $-1.42(1.21)$ \\
\hline & Recognition & 22 & $9.86(1.78)$ & $0.75(1.30)$ \\
\hline \multirow[t]{3}{*}{ BVMT } & Immediate recall & 21 & $16.38(8.65)$ & $-1.10(1.17)$ \\
\hline & Delayed recall & 21 & $6.76(4.23)$ & $-1.13(1.47)$ \\
\hline & Recognition & 21 & $5.24(1.09)$ & $-0.44(1.18)$ \\
\hline \multirow[t]{2}{*}{$\mathrm{TMT}$} & Part A & 22 & $49.72(27.12)^{\mathrm{a}}$ & $-0.80(1.39)$ \\
\hline & Part B & 20 & $135.55(91.36)^{\mathrm{a}}$ & $-1.43(1.22)$ \\
\hline \multirow[t]{3}{*}{ Stroop } & Card 1 & 22 & $23.90(14.88)^{\mathrm{a}}$ & $-1.80(1.25)$ \\
\hline & Card 2 & 22 & $24.86(10.22)^{a}$ & $-1.35(1.20)$ \\
\hline & Card 3 & 22 & $34.09(11.88)^{\mathrm{a}}$ & $-1.17(1.41)$ \\
\hline \multirow[t]{2}{*}{ Digit Span } & Original order & 22 & $5.00(1.07)$ & $-0.01(0.77)$ \\
\hline & Reversed order & 22 & $3.45(0.80)$ & $-0.42(0.50)$ \\
\hline \multirow[t]{2}{*}{ COWAT } & Phonologic & 22 & $24.14(9.77)$ & $-1.48(0.84)$ \\
\hline & Semantic & 21 & $14.38(4.65)$ & $-1.39(0.97)$ \\
\hline Symbol Digit & - & 22 & 38.45 (14.29) & $-1.86(1.00)$ \\
\hline Five Point & - & 22 & $19.64(7.21)$ & $-1.47(0.87)$ \\
\hline Grooved & Dominant hand & 19 & $87.42(22.80)^{a}$ & $-1.43(1.27)$ \\
\hline Pegboard & Non-dominant hand & 21 & $108.10(35.89)^{\mathrm{a}}$ & $-1.70(1.15)$ \\
\hline
\end{tabular}

aTask execution score measured by time in seconds.

BDI, Beck Depression Inventory; BVMT, Brief Visual Memory Test; COWAT, Controlled Oral Word Association Test; HVLT, Hopkins Verbal Learning Test; STAl, State-Trait Anxiety Inventory; TMT, Trail-Making Test.

TABLE 4 | Correlation between SIICl values and inhibitory control main neuropsychological test results (Spearman's correlation coefficient).

\begin{tabular}{llrl}
\hline $\begin{array}{l}\text { Neuropsychological tests (inhibitory control } \\
\text { assessment) }\end{array}$ & & \multicolumn{2}{c}{ SIICI } \\
\cline { 3 - 4 } & & rho & $\boldsymbol{p}$-Value \\
\hline Stroop Card 3 & Time & 0.080 & 0.611 \\
& Z-score & -0.019 & 0.904 \\
COWAT phonologic & Raw score & -0.407 & $\mathbf{0 . 0 0 7}$ \\
COWAT semantic & Z-score & -0.487 & $\mathbf{0 . 0 0 1}$ \\
& Raw score & -0.314 & $\mathbf{0 . 0 4 7}$ \\
Symbol digit & Z-score & -0.300 & $\mathbf{0 . 0 5 9}$ \\
Five point & Raw score & -0.274 & 0.078 \\
& Z-score & -0.385 & $\mathbf{0 . 0 1 1}$ \\
Grooved Pegboard dominant hand & Raw score & -0.129 & 0.414 \\
& Z-score & -0.129 & 0.414 \\
Grooved Pegboard Non-dominant hand & Time & 0.212 & 0.207 \\
& Z-score & -0.151 & 0.370 \\
& Time & 0.031 & 0.845 \\
& Z-score & -0.121 & 0.449
\end{tabular}

SIICl, Short-interval intracortical inhibition; COWAT, Controlled Oral Word Association Test.

year after TBI). Although there are many mechanisms involved in the development and evolution of DAI, such as diffuse vascular injury and blood-brain barrier disruption that could also interfere with the function of the neural circuitry, the paucity of studies on neurophysiological changes after moderate and severe DAI prevents comparison.

From the CE assessment perspective, pp-TMS using short ISI applied to the motor cortex can indirectly evaluate inhibitory processes mediated by GABAergic circuits (26). The altered SIICI results we found drove us to consider a possible association of

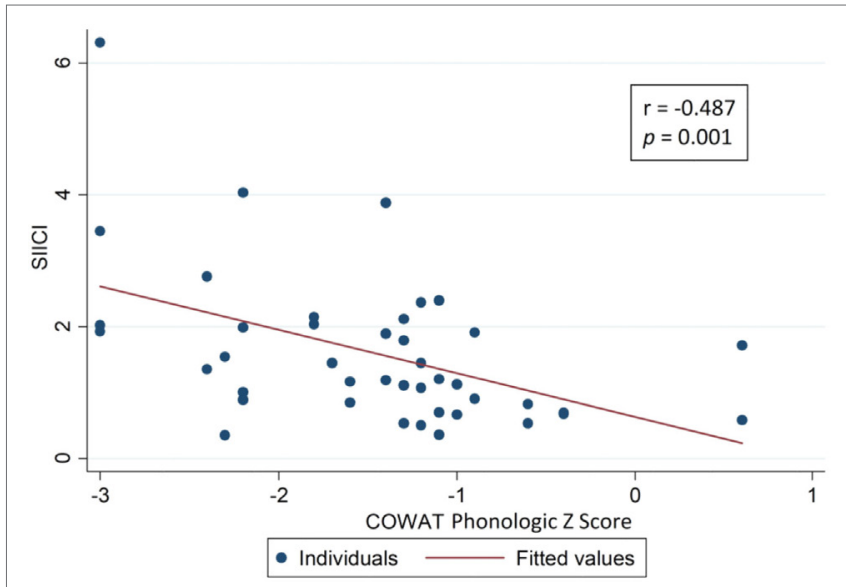

FIGURE 2 | Correlation between short-interval intracortical inhibition (SIICI) values and Controlled Oral Word Association Test (COWAT) phonologic test results.

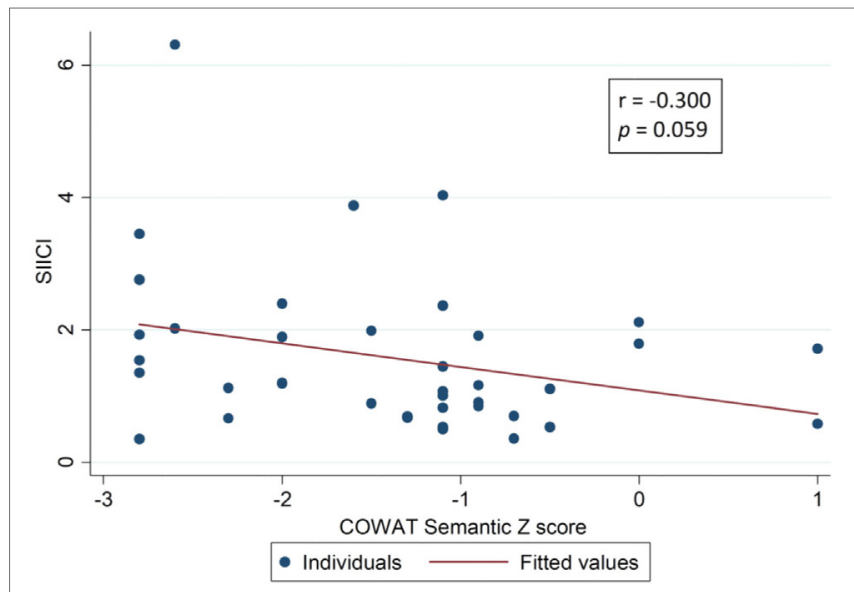

FIGURE 3 | Correlation between short-interval intracortical inhibition (SIICl) values and Controlled Oral Word Association Test (COWAT) semantic test results.

it with dexterity alterations (Grooved Pegboard Test scores) as specific motor task controlling involves intracortical inhibition process by activating a few selective cells and barring other motor neurons (32). The statistical analysis showed that it was not significant even though patients with TBI often present associated motor and cognitive injuries due to the various mechanisms of trauma $(4,33,34)$.

Only few neuropsychological tests showed results within the average expected. Nevertheless, the recognition on visual memory (BVMT) and the original order of Digit Span are rather simple tests which might have the results overestimated, considering that the city we held this study in has a high schooling rate. All other aspects, such as information processing speed, selective and task-switching attention, episodic and working memory, verbal fluency, and inhibition process, were all impaired on DAI group, even though it was not possible to establish a relation between the also altered SIICI values. 


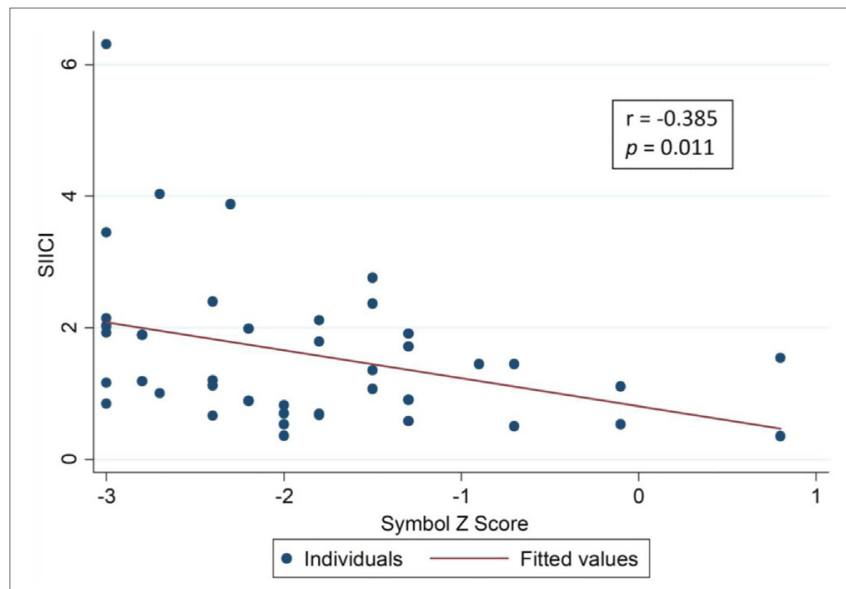

FIGURE 4 | Correlation between short-interval intracortical inhibition (SIICI) values and Symbol Digit test results.

It seems that the attention and memory impairment in DAI are not only affected by intracortical inhibition (GABAergic) and facilitation (glutamatergic) processes but also by many other circuits with complex influences that could not be fully identified in this study. Also, CE assessments can only be performed on a single area (the motor cortex), while cognitive tasks activate different areas of the brain at the same time in a complex pattern.

Another limitation of our study for correlating CE and neuropsychological data is the limited sample size $(n=22)$, so further studies with larger sample sizes are needed to elucidate this problem. Despite there being only a few statistically significant correlation of these aspects (Table 4), post-TBI cognition recovery still needs investigation, and unfortunately, the post-trauma setting restrained knowledge on how these individuals were before the incident and on any discrepancies from the neuropsychological perspective.

When considering the control group CE data alone, some values can be interpreted as already abnormal. Still, they are not pathological and just out of what would be considered "common"/"norm." It is worth mentioning that even in healthy individuals, CE values are subject to a large variability or be influenced by many environmental issues (lack of sleep, caffeine consumption, etc.) $(17,35)$. Minutely, as expected in normative data, there will be $5 \%$ of healthy sample that will not be within confidence interval $(95 \% \mathrm{CI})$, by definition $(36,37)$. For this study, the control group was considered "healthy" from TBI perspective and free from any other CNS disease, so that the comparison we wanted to make was DAI patients and healthy (non-TBI) subjects.

Revising potential outliers on DAI group, they seemed mathematically outliers, however, not actual clinically outliers. This would be explained by the fact that maximum values for SIICI in healthy subjects over 50 years can be up to 6.7 and up to 3.5 for those who are under 50 years (17).

Regarding the mechanisms of TBI, Almeida-Suhett and collaborators (38) suggested that the loss of GABAergic interneurons after mild TBI reflects a reduction of neuronal inhibition. Miller and collaborators (39) also suggested an influence of mild
TBI on intracortical inhibition, measured by silent period (SP) parameters. Bernabeu and collaborators (40) showed the abnormal corticospinal excitability in patients with DAI where motor recovery was related to the severity of TBI (the lower the severity, the better the motor recovery) using input-output curves and SP. These studies address mild TBI with a similar change in inhibition parameter as we found in moderate and severe TBI.

As the inhibition processes involve GABA-mediated circuitry, it is reasonable to infer that DAI pathophysiology itself (disruption of axons) may deplete GABA, contributing to a defective inhibition of neural system on the chronic phase of DAI. For better evidence of GABA depletion, we would recommend further studies measuring GABA noninvasively, if possible, using MR spectroscopy.

We acknowledge that measuring MEPs using cancelation techniques, such as the triple stimulation method, would provide better reliability and more accurate measurements of central conduction times and MEP amplitudes. However, our main aim was to have a concise and brief assessment of CE parameters that would provide a more general view of the excitability status on DAI patients. It is interesting that the present study could find altered intracortical inhibition on these patients but the imbalance of inhibition and facilitation processes is not limited only to GABA-mediated or glutamate-mediated pathways, suggesting that different mechanisms may influence on TBI recovery.

\section{ETHICS STATEMENT}

CAPPesq-Comissao de Etica para Analise de Projetos de Pesquisa do Hospital das Clinicas da Faculdade de Medicina da Universidade de Sao Paulo. Protocol \#707.642. All eligible patients were interviewed and invited to voluntarily participate in our study. All aspects of our study were explained and clarified. Those who accepted gave written informed consent upon recruitment in compliance with Declaration of Helsinki. Not applicable.

\section{AUTHOR CONTRIBUTIONS}

All of the authors contributed to patient recruitment, data analysis, and preparation of the manuscript.

\section{ACKNOWLEDGMENTS}

We would like to express our gratitude to our Service of Interdisciplinary Neuromodulation colleagues Rosa Rios, RN, and secretary Sandra Falcon for their help in patient care and scheduling. We would also like to thank psychologist Thiago Pedroso for assistance with neuropsychological assessments.

\section{FUNDING}

Cintya Yukie Hayashi-funded by CAPES Postgraduate Scholarship Program (Coordination for Improvement of Higher Education Staff). Andre Russowsky Brunoni is supported by the following grants: National Alliance for Research on Schizophrenia and Depression 2013 Young Investigator from the Brain \& Behavior 
Research Foundation (NARSAD, Grant Number 13/20493), FUNDAÇÃO DE AMPARO A PESQUISA DO ESTADO DE SAO PAULO 2012 Young Researcher from the Sao Paulo State
Foundation (FAPESP, Grant Number 12/20911-5) and National Council for Scientific and Technological Development (CNPq, Grant Number 13/470904, 459077/2014).

\section{REFERENCES}

1. Andrade AF, Figueiredo EG, Teixeira MJ, Taricco MA, Amorim RLO, Paiva WS. Neurotraumatologia. Rio de Janeiro: Guanabara Koogan (2015).

2. World Health Organization (WHO). World Health Statistics 2008 [Document on the Internet]. Geneva: World Health Organization (2008).

3. Rabinowicz AR, Levin HS. Cognitive sequelae of traumatic brain injury. Psychiatr Clin North Am (2014) 37:1-11. doi:10.1089/neu.2014.3555

4. Hyder AA, Wunderlich CA, Puvanachandra P, Gururaj G, Kobusingye OC. The impact of traumatic brain injuries: a global perspective. NeuroRehabilitation (2007) 22:341-53.

5. Johnson VE, Stewart W, Smith DH. Axonal pathology in traumatic brain injury. Exp Neurol (2013) 246:35-43. doi:10.1016/j.expneurol.2012.01.013

6. Gennarelli TA, Graham DI. Neuropathology of the head injuries. Semin Clin Neuropsychiatry (1998) 3:160-75.

7. Yasokawa YT, Shinoda J, Okumura A, Nakayama N, Miwa K, Iwama T. Correlation between diffusion-tensor magnetic resonance imaging and motor-evoked potential in chronic severe diffuse axonal injury. J Neurotrauma (2007) 24:163-73. doi:10.1089/neu.2006.0073

8. Castel-Lacanal E, Tarri M, Loubinoux I, Gasq D, de Boissezon X, Marque P, et al. Transcranial magnetic stimulation in brain injury. Ann Fr Anesth Reanim (2014) 33:83-7. doi:10.1016/j.annfar.2013.11.006

9. Wank JY, Bakhadirov K, Devous MD Sr, Abdi H, McColl R, Moore C. Diffusion tensor tractography of traumatic diffuse axonal injury. Arch Neurol (2008) 65:619-26. doi:10.1001/archneur.65.5.619

10. Pascual-Leone A, Tormos JM, Julian K, Tarazona F, Canete C, Catala MD. Study and modulation of human cortex excitability with transcranial magnetic stimulation. J Clin Neurophysiol (1998) 15:333-43. doi:10.1097/00004691199807000-00005

11. Liuzzi G, Horniss V, Lechner P, Hoppe J, Heise K, Zimerman M, et al. Development of movement-related intracortical inhibition in acute to chronic subcortical stroke. Neurology (2014) 82:198-205. doi:10.1212/WNL. 0000000000000028

12. Croarkin PE, Nakonezny PA, Husain MM, Melton T, Buyukdura JS, Kennard BD. Evidence for increased glutamatergic cortical facilitation in children and adolescents with major depressive disorder. JAMA Psychiatry (2013) 70:291-9. doi:10.1001/2013.jamapsychiatry.24

13. Mhalla A, de Andrade DC, Baudic S, Perrot S, Bouhassira D. Alteration of cortical excitability in patients with fibromyalgia. Pain (2010) 149:495-500. doi:10.1016/j.pain.2010.03.009

14. Powers KC, Cinelli ME, Kalmar JM. Cortical hypoexcitability persists beyond the symptomatic phase of a concussion. Brain Inj (2014) 28:465-71. doi:10.3109/ 02699052.2014 .888759

15. Dermitas-Tatlidede A, Vahabzadeh-Hagh AM, Bernabeu M, Tormos JM, Pascual-Leone A. Noninvasive brain stimulation in traumatic brain injury. J HeadTraumaRehabil(2010)27:274-92.doi:10.1097/HTR.0b013e318217df55

16. Cantu D, Walker K, Andresen L, Taylor-Weiner A, Hampton D, Tesco G, et al. Traumatic brain injury increases cortical glutamate network activity by compromising GABAergic control. Cereb Cortex (2015) 25:2306-20. doi:10.1093/cercor/bhu041

17. Cueva AS, Galhardoni R, Cury RG, Parravano DC, Correa G, Araujo H, et al. Normative data of cortical excitability measurements obtained by transcranial magnetic stimulation in healthy subjects. Neurophysiol Clin (2016) 46:43-51. doi:10.1016/j.neucli.2015.12.003

18. Gorenstein C, Andrade L. Validation of a Portuguese version of the Beck depression inventory and the state-trait anxiety inventory in Brazilian subjects. Braz J Med Biol Res (1996) 29:453-7.

19. Spielberg CD, Gorsuch RL, Luschene R. Test Manual for the State-Trait Anxiety Inventory. Palo Alto: Consulting Pshychologist Press (1960).

20. Beck AT, Erbaugh J, Ward CH, Mock J, Mendelsohn M. An inventory for measuring depression. Arch Gen Psychiatry (1961) 4:561-71. doi:10.1001/ archpsyc.1961.01710120031004
21. Miotto EC, Campanholo KR, Rodrigues MM, Serrao VT, Lucia M, Scaff M. Hopkins verbal learning test-revised and brief visuopatial memory test-revised: preliminary normative data for the Brazilian population. Arq Neuropsiquiatr (2012) 70:962-5. doi:10.1590/S0004-282X201200120001

22. Campanholo KR, Romao MA, Machado MAR, Serrao VT, Coutinho DGC, Benute GRG, et al. Performance of an adult Brazilian sample on trail making test and Stroop test. Dement Neuropsychol (2014) 8:26-31. doi:10.1590/ S1980-57642014DN81000005

23. Wechsler D. Wechsler Adult Intelligence Scale-Third Edition (WAIS-III). New York: Psychological Corporation (1997).

24. Strauss E, Sherman EMS, Spreen O. A Compendium of Neuropsychological Tests: Administration, Norms and Commentary. New York: Oxford University Press (2006).

25. Tiffin J. Purdue Pegboard: Examiner Manual. Chicago: Science Research Associates (1968).

26. Chen R. Interactions between inhibitory and excitatory circuits in the human motor córtex. Exp Brain Res (2004) 154:1-10. doi:10.1007/s00221-0031684-1

27. Rothwell JC, Hallett M, Berardelli A, Eisen A, Rossini P, Paulus W. Magnetic stimulation: motor evoked potentials. The international federation of clinical neurophysiology. Electroencephalogr Clin Neurophysiol Suppl (1999) 52:97-103.

28. Rossini PM, Burke D, Chen R, Cohen LG, Daskalakis Z, Di Iorio R, et al. Non-invasive electrical and magnetic stimulation of the brain, spinal cord, roots and peripheral nerves: basic principles and procedures for routine clinical application. An update report from IFCN committee. Clin Neurophysiol (2015) 126:1071-107. doi:10.1016/j.clinph.2015.02.001

29. Lefaucheur JP. Use of repetitive transcranial magnetic stimulation in pain relief. Expert Rev Neurother (2008) 8:700-808. doi:10.1586/14737175. 8.5.799

30. Groppa S, Oliviero A, Eisen A, Quartarone A, Cohen LG, Mall V, et al. A practical guide to diagnostic trasncranial magnetic stimulation: report of an IFCN committee. Clin Neurophysiol (2012) 123:858-82. doi:10.1016/j. clinph.2012.01.010

31. Wilson JT, Pettigrew LE, Teasdale GM. Structured interviews for the Glasgow outcome scale and the extended Glasgow outcome scale: guidelines for their uses. JNeurotrauma (1998) 15:573-85. doi:10.1089/neu.1998. 15.573

32. Abruzzese G, Trompetto C. Clinical and research methods for evaluating cortical excitability. JClin Neurophysiol (2002) 19:307-21. doi:10.1097/00004691-200208000-00005

33. Zaninotto AL, Vincentini JE, Solla DJ, Silva TT, Guirado VM, Feltron F, et al. Visuospatial memory improvement in patients with diffuse axonal injury (DAI): a 1-year follow-up study. Acta Neuropsychiatr (2017) 29:35-42. doi:10.1017/neu.2016.29

34. Vieira RC, Paiva WS, de Oliveira DV, Teixeira MJ, de Andrade AF, de Sousa RM. Diffuse axonal injury: epidemiology, outcome and associated risk factors. Front Neurol (2016) 7:178. doi:10.3389/fneur.2016.00178

35. Wasserman EM. Variation in the response to transcranial magnetic brain stimulation in the general population. Clin Neurophysiol (2002) 113:1165-71. doi:10.1016/S1388-2457(02)00144-X

36. Dwason B, Trapp RG. Basic \& Clinical Biostatistics. New York: McGraw-Hill (2004).

37. Glantz SA. Primer of Biostatistics. New York: McGraw-Hill (2012).

38. Almeida-Suhett CP, Prager EM, Pidoplichko V, Figueiredo TH, Marini AM, $\mathrm{Li}$ Z, et al. Reduced GABAergic inhibition in the basolateral amygdala and the development of anxiety-like behaviors after mild traumatic brain injury. PLoS One (2014) 9:e102627. doi:10.1371/journal.pone.0102627

39. Miller NR, Yasen AL, Maynard LF, Chou LS, Howell DR, Christie AD. Acute and longitudinal changes in motor cortex function following mild traumatic brain injury. Brain Inj (2014) 28:1270-6. doi:10.3109/02699052.2014. 915987 
40. Bernabeu M, Dermitas-Tatlidede A, Pisso E, Lopez R, Tormos JM, PascualLeone A. Abnormal corticospinal excitability in traumatic diffuse axonal brain injury. J Neurotrauma (2009) 26:2185-93. doi:10.1089/neu.2008.0859

Conflict of Interest Statement: This research was conducted in the absence of any commercial or financial considerations that could be construed as a potential conflict of interest.
Copyright () 2018 Hayashi, Neville, Rodrigues, Galhardoni, Brunoni, Zaninotto, Guirado, Cueva, de Andrade, Teixeira and Paiva. This is an open-access article distributed under the terms of the Creative Commons Attribution License (CC BY). The use, distribution or reproduction in other forums is permitted, provided the original author(s) and the copyright owner are credited and that the original publication in this journal is cited, in accordance with accepted academic practice. No use, distribution or reproduction is permitted which does not comply with these terms. 